\title{
Action of tizanidine on responses of forearm flexors and extensors to torque disturbances
}

\author{
R MACKEL, ${ }^{*}$ EE BRINK, ${ }^{* *}$ AND Y NAKAJIMA** \\ Department of Neurology, Technical University of Munich, Moehlstrasse 28, D-8000 Munich 80 FRG
}

SUMMARY The effects of tizanidine on the electromyographic responses of forearm flexors and extensors to torque disturbances were studied in normal subjects. Tizanidine had a strong depressive action on all the reflex responses, and on muscle background activity. It is concluded that the action on reflexes is not specific, but secondary to decreased spinal cord excitability.

A significant myotonolytic action of tizanidine, a centrally acting ${ }^{\prime}$ benzothiadazol derivative (5-chloro-4-[2-imidazolin-2-yl-amino] -2,1,3-benzothiadiazole), has been reported from animal experiments ${ }^{12}$ and clinical observations ${ }^{3-5}$ : its use is regarded as beneficiary for spasticity. ${ }^{2-5}$ There is less agreement as to its actions on reflex mechanisms: it is reported variously to have little or no effect on spinal reflexes (cat $\left.{ }^{1}\right)$, differential effects on early versus late responses to stretch $\left(\mathrm{cat}^{2}\right)$, or actions on stretch reflexes independent of those on muscle tone (humans ${ }^{3}$ ). Some of the disparity undoubtedly stems from the variety of preparations used, each associated with abnormal muscle tone. The animal experiments have involved anaesthetised, ${ }^{1}$ spinalised, ${ }^{1}$ decerebrate, ${ }^{2}$ or drug-treated ${ }^{1}$ preparations, while human studies have been limited to patients suffering from various forms of spasticity..$^{3-5}$ In the latter studies, effects of longterm antispastic medication might be expected to obscure assessment of the action of tizanidine.

To avoid the bias of abnormal muscle tone and gain insight into the normal physiological action of tizanidine, the present study examines tizanidine's effects in normal subjects, on normally-functioning

\footnotetext{
*Present address of R. Mackel, to whom correspondence should be addressed: Department of Neurology, The New York-Hospital Cornell Medical Center, 525 East 68th Street, New York, N.Y. 10021, USA.

**E.E.B. and Y.N. were recipients of Alexander von Humboldt fellowships. Present address of E.E.B.: The Rockefeller University, 1230 York Avenue, New York, N.Y. 10021, USA.

Present address of Y.N.: Department of Physiology, School of Medicine, Chiba University, Chiba 280, Japan.
}

reflex mechanisms. The reflexes were elicited by torque perturbations stretching either the elbow flexors or extensors: such sudden displacements produce segmented electromyographic responses in the stretched muscles, at latencies shorter than voluntary reaction times. ${ }^{67}$ The earliest responses (named $\mathrm{M}^{8}$ ) corresponds to the monosynaptic stretch reflex, ${ }^{6910}$ while the later responses (M2, $\mathrm{M}^{8}$ ) may also be spinal reflexes since such responses can be elicited in spinal animals (see also ref. 13). ${ }^{112}$ The reflexes are under supraspinal control, being affected by instructions to the subject ${ }^{14-16}$ and by supraspinal lesions. ${ }^{17} 18$ The present study sought to compare the effects of tizanidine on reflexes and muscle tone, on early and late reflexes, and to see whether tizanidine interfered differentially with instructions to the subject.

\section{Methods}

Subjects. Experiments were conducted on 14 healthy subjects (five females and nine males) aged between 23 and 28 years. The weight of the subjects ranged between 45 and $60 \mathrm{~kg}$ (females) and between 70 and $85 \mathrm{~kg}$ (males). Ten subjects (four females and six males) were acutely studied before and after the intramuscular (im) administration of $1 \mathrm{mg}$ of tizanidine, which amount was given regardless of body weight. Systolic/diastolic blood pressure, pulse rate, behavioural responses and subjective reports from the subjects were also noted. The control data were collected prior to the drug administration. At least 30 minutes elapsed between drug administration and the first experimental session, at which time the maximal effects were seen. Observations were continued to two hours after injection. Additional control observations (without tizanidine) were made on four subjects (one female, three males), to assess the relation of the muscle background activity alone to the size of the stretch-induced reflex activity and to assess variations in activity over time. Finally, for 
additional comparison, nine other subjects were given a mild relaxant (chlormezanone) after which they were slightly drowsy, and were tested under the same conditions. All investigations were performed with the full consent of the subjects and according to the guiding principles of the Declaration of Helsinki. The subjects were informed of the effects which might occur following drug administration.

Stimulation. A torque motor was used to displace the forearm of the subjects' preferred arm. The subjects were seated, their elbows resting on pads mounted on the frame of the machine (see fig 1A). The forearm which was displaced was fixed at the wrist to the arm of the torque motor (machine arm). The subjects held their arms so as to form a $90^{\circ}$ angle between the lower and upper arm (that is a $45^{\circ}$ angle with respect to the horizontal), in quasi-isometric contraction of the flexor muscles. Forearm position was measured as angular displacement of the machine arm (by means of a potentiometer), was monitored on an oscilloscope, and was under the subject's visual control. Torque pulses were applied to the forearm to produce sudden downward or upward displacements, stretching respectively the forearm flexors or extensors.

The initial position $\left(90^{\circ}\right.$ angle between lower and upper arm) was held against gravity alone, or against an additional preload torque of 1.8 Newton meters $(\mathrm{Nm}$, downward directed) for experiments stretching flexors or of 6.5 $\mathrm{Nm}$ (upward directed) for experiments stretching extensors. Both the weight of the machine arm and of the subject's forearm contribute to the torque at the elbow. The calculated torque due to the machine arm (checked against measurements made with a calibrated spring) ranged from 1.02 to $1.09 \mathrm{Nm}($ mean $=1.05 \mathrm{Nm})$. Torque due to the subjects' forearms was calculated for the same and matched subjects $(n=15)$ from measurements of forearm lengths and body weights, with use of anthropometric tables. ${ }^{19}$ These values ranged from 0.94 to $1.99 \mathrm{Nm}$ (mean: $1.5 \mathrm{Nm}$ ). Thus, the total torque due to gravity for the subjects ranged from 1.96 to $3.08 \mathrm{Nm}$ (mean: $2.55 \mathrm{Nm}$ ). The torque due to gravity adds to the additional torque for
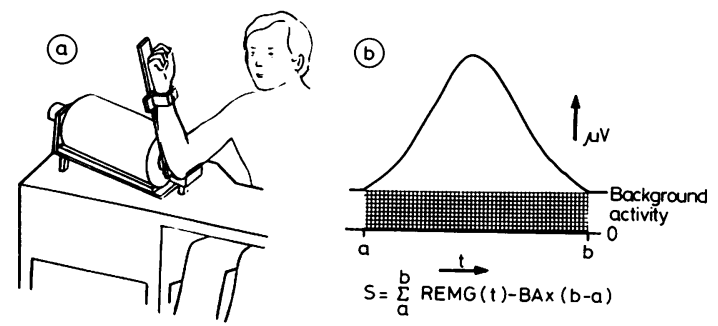

Fig 1 (A). Experimental arrangement for applying torque perturbations to the subjects' forearms. Details in text. (B). Schematic illustration of the procedure used to quantify the muscle reflex responses. The EMG activity attributed to the reflex response (S) equals the integral of the rectified and averaged EMG (REMG) calculated over the response interval (from time a to time b) minus the resting EMG activity occurring over that interval $(B A \times(b-a))$. Average background activity $(B A)$ was calculated over an interval preceding the disturbance pulse. flexor experiments and subtracts from it for extensor experiments. Thus, the average preloads were $2.55 \mathrm{Nm}$ (gravity alone) or $\mathbf{4 . 3 5} \mathrm{Nm}$ (downward) for flexor experiments, or $3.95 \mathrm{Nm}$ (upward) for extensor experiments. These preloads are relatively small compared to the torques at the elbow produced when the flexors exert their maximum force (at least $40-70 \mathrm{Nm}$ or more, estimated from the data of other authors), ${ }^{20-22}$ and were selected to enhance the reflexes ${ }^{73}$ without fatiguing the muscles.

The disturbance pulses used to elicit the reflexes were $100 \mathrm{~ms}$ long, and of $6.3 \mathrm{Nm}$ for flexor experiments or 5.4 $\mathrm{Nm}$ for extensor experiments. Rise time to reach maximal torque was $13-20 \mathrm{~ms}$, as judged from the time to peak acceleration measured from accelerometers placed on the subjects' forearms or on the machine arm. The torque pulses were chosen to produce as rapid as possible displacements and larger reflex responses. ${ }^{23}$ The average speed during the interval in which the displacement could be expected to influence the responses (that is the first 80 $\mathrm{ms}$, allowing $20 \mathrm{~ms}$ monosynaptic reflex time (see later), to affect responses measured out to $100 \mathrm{~ms}$ ), was about 90 $100 \% \mathrm{~s}$ in flexor experiments and $70 \% \mathrm{~s}$ in extensor experiments. The velocity was not constant over time, because of the effect of acceleration due to gravity, and if, for example, measured over the first $20 \mathrm{~ms}$ (before reflex contractions could contribute), average speed in flexor experiments was only about $45-60 \%$ s.

Procedure. The subjects were instructed to compensate for the perturbation (to "resist") or to follow (to "let-go"). Normally, with the "resist" instruction, all the segmented muscle reflex responses (M1, M2, M3) plus later voluntary activity occur, while with the "let go" instruction the later (M2, M3) components especially and voluntary activity are suppressed, ${ }^{14-16}$ when stimulus onsets are predictable. ${ }^{24}$ Typically, the subject was instructed how to respond and allow practice, then the initial conditions (position, preload) were imposed, and the responses to a run of eight disturbance pulses collected. The torque pulses were delivered at fairly regular intervals, and were therefore rather predictable. The subject was allowed a brief rest between successive trials.

Voluntary reaction times for EMG responses to a somesthetic stimulus were measured to draw a border line between the reflex and voluntary compensatory EMG activity. For this, the subjects were instructed to move their forearms as quickly as possible from the initial position on perception of the stimulus. The stimulus was a weak, brief $(0.55 \mathrm{Nm}, 9 \mathrm{~ms})$ torque pulse that itself produced no reflex responses. The latency was measured from the onset of the pulse to the earliest increase in EMG activity above background, and ranged from 95 to $165 \mathrm{~ms}$ with means of 127 $\mathrm{ms} \pm 22 / \mathrm{SD}$ and $124 \pm 22 \mathrm{~ms}$ for brachialis and triceps, respectively. However, since other authors ${ }^{14}$ is have reported voluntary increase of flexor EMG as early as $70-80 \mathrm{~ms}$, voluntary activity could contribute to the latest (M3) response component.

Recording and treatment of data. Electromyographic activity was recorded bipolarly with silver wires (diameter: 150 microns), insulated but for $2-3 \mathrm{~mm}$ at the tip, that were inserted percutaneously into the muscles. One pair of wires was placed into the brachialis muscle, a pure flexor of the forearm, and another pair of wires into the antagonistic 
medial or lateral heads of triceps, pure extensors of the forearm. The electromyographic activity was amplified and filtered $(\times 1000$, band width $100-2000 \mathrm{~Hz})$ and stored on magnetic tape, together with an analog signal of the angular displacement of the machine arm, and a record of the acceleration of the forearm (measured with Grass accelerometers). All data, raw and averaged (see below) were monitored on oscilloscopes and a polygraph during the experimentation.

For analysis EMG activity was full-wave rectified, then sampled over $200 \mu$ s every $0.8 \mathrm{~ms}$, averaged $(\mathrm{n}=8)$ and smoothed (by means of a 3-point running average procedure) using a Nicolet 1074 averager with inbuilt data manipulation system. Displacement and acceleration data were similarly sampled and averaged. The EMG reflex responses (M1, M2, M3) were identified, and latencies measured from the onset of the torque pulse (which typically preceded onset of measurable machine arm displacement by $3-5 \mathrm{~ms})$. Typically, M1 responses began at $23 \mathrm{~ms}$ and lasted until $44 \mathrm{~ms}$ after onset of the torque pulse (the M1 often appearing double-peaked after rectification), the M2 lasted from 47 to $73 \mathrm{~ms}$, and the M3 from 74 to $97 \mathrm{~ms}$ (average values from control data, similar for all test conditions, and for triceps as well as brachialis. An example is schematically illustrated in Fig 2A). Sometimes M3 responses did not appear as peaks clearly definable from the $\mathrm{M} 2$ responses. In these cases, activity occurring within the typical M3 onset and offset latencies was considered to be the M3 response. The areas under the response peaks were determined using the Nicolet 1074 inbuilt integration system. From these values, the background activity over the individual response intervals was subtracted to give the final integral values for the reflex responses. This procedure is illustrated in fig $1 \mathrm{~B}$. Average background EMG activity was determined over the $850 \mathrm{~ms}$ preceding the disturbance pulse. The data obtained before and after drug administration were tested using a Student's $t$ test for dependent samples, with correction for small sample size. ${ }^{25}$

\section{Results}

General observations. The most commonly observed side-effects of tizanidine were a reduction of systolic blood pressure ( $8 / 10$ subjects) and drowsiness of the subjects $(9 / 10)$. The drop in blood pressure ranged between 10 and $40 \mathrm{~mm} / \mathrm{Hg}$ (mean: 20 $\mathrm{mm} / \mathrm{Hg}$, that is a $16 \%$ decrease), being larger with higher initial systolic pressures. Hypotensive effects of tizanidine were reported earlier $r^{3}$ but occurred less commonly than in the present study, probably because the drug was given orally in the earlier study. Care should be taken when giving tizanidine im to patients with low blood pressure or patients under anti-hypertensive therapy. The sedative (drowsiness) effects of the drug were also observed ${ }^{3}$ earlier, and are supported by the EEG studies in man of Matejcek (internal report of Sandoz Ltd, Basel, Switzerland) who observed an increase of slow wave EEG activity and a decrease of the alpha-activity following oral administration of
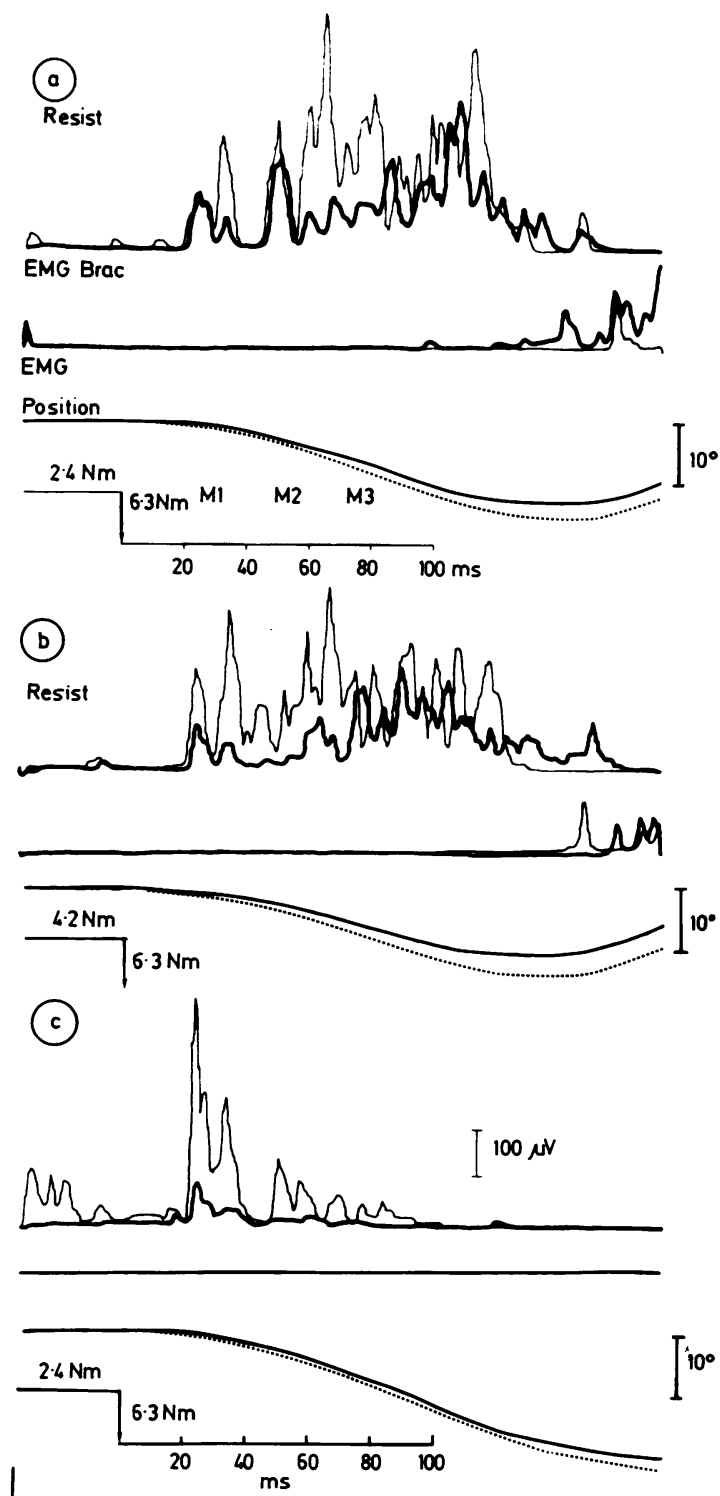

Fig 2 Depressive action of tizanidine on responses of flexor muscles to torque perturbations. All data from one subject. ( $A$ and $B)$, responses obtained under "resist" instructions, with different preloads: $2 \cdot 4 \mathrm{Nm}$ in $(A)$ and $4 \cdot 2$ $\mathrm{Nm}$ in $(B)$. (C) responses obtained under "let go" instructions. Top set of traces in $A, B, C$ are rectified and averaged EMG responses from brachialis muscle, before (thin lines) and after (thick lines) administration of tizanidine. Second set of traces, triceps EMG. Third set, mechanical deviation of the forearm: continuous line, control; broken line, with tizanidine. Latencies and durations of the M1,M2 and M3 from the onset of the torque pulse $(6.3 \mathrm{Nm})$ are schematically illustrated under the position traces in $A$. 


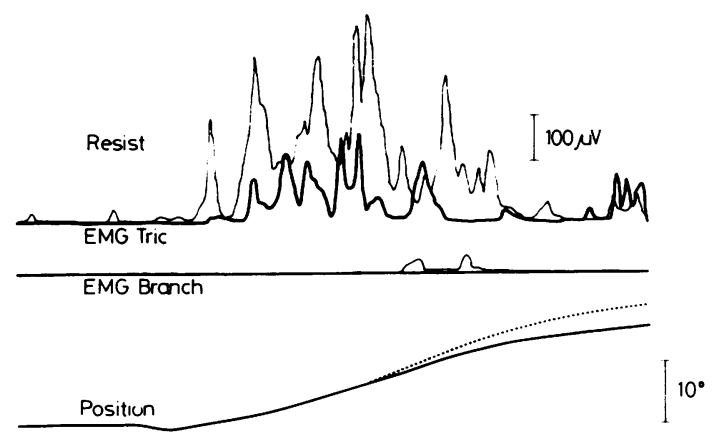

$$
\begin{array}{lllll}
5.4 \mathrm{Nm} & 20 \quad 40 \\
3.7 \mathrm{Nm} & & & 60 \quad 80 \quad 100
\end{array}
$$

Fig 3 Depression of extensor muscle responses to torque perturbations by tizanidine. Figure arrangement as in fig 2 , except that top set of traces are from triceps and second set from brachialis. Torque pulse and mechanical deviation are in the opposite direction compared to fig 2.

tizanidine. The strongest sedating and myotonolytic (see next section) effects were observed about one hour following im application. Both effects decreased during the second hour. The hypotensive effects seemed to outlast the myotonolytic effects, although they were not measured beyond two hours following drug application. Significant alterations in pulse rate were not observed. Dryness of the mouth was reported in two cases. Tizanidine was not found to have an effect on the voluntary reaction times to somesthetic stimuli.

Tizanidine action on reflex responses and muscle background activity. Tizanidine strongly depressed the EMG reflex responses. This is illustrated in fig 2 for experiments involving stretch of flexors, and in fig 3 for experiments in which extensors were stretched. In these figures, the rectified and averaged responses from the agonist muscle are the top set of traces, from the antagonist are the second set, and the angular displacement are the lowest traces. The thin lines are responses before tizanidine, upon which the responses with tizanidine (heavy lines) are superimposed. From fig 2, obtained from one subject, it can be seen that the reflex responses (occurring within less than $100 \mathrm{~ms}$ ) are depressed under all experimental paradigms. In fig $2 \mathrm{~A}$ and $\mathrm{B}$, in which the subject resists the disturbance, while holding an initial position against gravity alone (fig $2 \mathrm{~A}$ ) or with an additional preload (fig $2 \mathrm{~B}$ ), all the brachialis reflex components, M1, M2 and M3, are clearly depressed after the administration of tizanidine. Additionally, the displacement records show during the later phases of displacement a larger mechanical deviation to the torque pulses following medication (dotted lines) then prior to it. This probably reflects the decreased muscle tone and lowered reflex efficacy. The records from the antagonist muscle (triceps) show that after as before tizanidine administration, there was no co-activation of the antagonists during the flexor responses. The records of fig $2 \mathrm{C}$ were obtained under the "let go" instructions, in which experiments the subjects held the initial position against gravity alone. In the control records, the voluntary EMG activity that occurs in "resist" trials at about $100 \mathrm{~ms}$ is completely lacking, and no M2 or M3 activity above background level occurs. The short-latency M1 response, however, is relatively unchanged. After the administration of tizanidine, the $\mathrm{M} 1$ is considerably reduced.

Figure 3 shows that similar results were obtained when extensors were stretched. These were tested only under "resist" instructions. Again, all reflex components were reduced, and the later mechanical deviation was greater after medication.

In total, tizanidine had a depressive action in $8 / 9$ subjects in the brachialis "resist" test (with preload due to gravity alone) and $7 / 8$ subjects in the test with an additional preload; in $8 / 9$ subjects in the brachialis "let go" test; and in $8 / 10$ subjects in the triceps "resist" test. No effect was seen in one subject (tested under all conditions), although sedating and hypotensive effects were apparent in that individual. In a second subject, no depressive effect was seen in the triceps test, although it was seen in the brachialis tests.

Tables 1 and 2 summarise the depressive actions of tizanidine, seen at $1 / 2$ to one hour after injection, when the effects were maximal. The tables therefore exclude the data for the subject where no effects were seen and for triceps experiments, from the second subject where no effects on triceps were seen. In the few cases where individual responses (notably M3) were poorly identifiable, these data could not be included, leading to the adjusted numbers in the tables. In table 1 , for each subject the overall reflex activity obtained in a trial was set at $100 \%$ (M1 + $M 2+M 3=100$ ), and the values for each component was expressed as \% of this total response. It should be recalled that because of the variation in torque due to gravity alone, preloads for the different subjects tested under the same conditions differed, varying by at most about $1 \mathrm{Nm}$. However, control observations ( $n=4$ subjects) showed that for anyone subject, a variation of $\pm 1 \mathrm{Nm}$ of preload torque about gravity alone or gravity plus added preload did not affect the normalised distribution of (brachialis) responses. Therefore, it was considered justifiable to group together the subjects' data. Also, in three of the "let-go" tests, a smaller load of 3.9 
Table 1 Distribution of reflex activity before and after im administration of tizanidine

\begin{tabular}{|c|c|c|c|c|c|c|c|c|}
\hline & \multicolumn{4}{|l|}{ Control } & \multicolumn{4}{|c|}{ Tizanidine } \\
\hline & \multicolumn{2}{|c|}{$\begin{array}{l}\text { M. Brachialis } \\
\text { Resist }\end{array}$} & \multirow[b]{2}{*}{$\begin{array}{l}\text { Let go } \\
69 \cdot 9 \\
\pm 30 \\
32 \cdot 5 \\
\pm 27 \cdot 3 \\
0 \\
\pm 0 \\
7\end{array}$} & \multirow{2}{*}{$\begin{array}{l}\begin{array}{l}\text { M. Triceps } \\
\text { Resist }\end{array} \\
15 \cdot 5 \\
\pm 11 \\
46 \cdot 5 \\
\pm 22 \\
37 \cdot 9 \\
\pm 27 \cdot 6 \\
7\end{array}$} & \multicolumn{2}{|c|}{$\begin{array}{l}\text { M. Brachialis } \\
\text { Resist }\end{array}$} & \multirow[b]{2}{*}{$\begin{array}{l}\text { Let go } \\
68 \cdot 0 \\
\pm 38 \cdot 8 \\
32 \cdot 9 \\
\pm 36 \\
0 \\
\pm 0 \\
7\end{array}$} & \multirow{2}{*}{$\begin{array}{l}\begin{array}{l}\text { M. Triceps } \\
\text { Resist }\end{array} \\
14 \cdot 0 \\
\pm 11 \cdot 3 \\
49 \cdot 3 \\
\pm 23 \cdot 3 \\
36 \cdot 7 \\
\pm 29 \cdot 8 \\
7\end{array}$} \\
\hline $\begin{array}{l}\text { M1 } \\
\text { M2 } \\
\text { M3 } \\
\text { N: } \\
100 \%\end{array}$ & $\begin{array}{l}25 \cdot 7 \\
\pm 9 \cdot 3 \\
41 \cdot 7 \\
\pm 10 \cdot 8 \\
32 \cdot 6 \\
\pm 8 \cdot 3 \\
7\end{array}$ & $\begin{array}{l}25 \cdot 0 \\
( \pm 5 \cdot 7) \\
44 \cdot 4 \\
( \pm 9 \cdot 6) \\
30 \cdot 6 \\
( \pm 8 \cdot 7) \\
6\end{array}$ & & & $\begin{array}{l}28 \cdot 1 \\
\pm 13 \\
37 \cdot 1 \\
\pm 12 \cdot 9 \\
34 \cdot 8 \\
\pm 13 \cdot 5 \\
7\end{array}$ & $\begin{array}{l}29 \cdot 6 \\
( \pm 9 \cdot 8) \\
39 \cdot 1 \\
( \pm 18 \cdot 2) \\
31 \cdot 3 \\
( \pm 18 \cdot 6) \\
6\end{array}$ & & \\
\hline
\end{tabular}

Table 2 Reflex activity following im administration of tizanidine, expressed as percent of control values. (Control $=$ $100 \%)$

\begin{tabular}{|c|c|c|c|c|c|}
\hline & & $B A$ & $M 1$ & $M 2$ & M3 \\
\hline $\begin{array}{l}\text { M. Brachalis } \\
\text { M. Triceps }\end{array}$ & $\begin{array}{l}\text { Resist } \\
\text { Let go } \\
\text { Resist }\end{array}$ & $\begin{array}{c}47 \cdot 6 \pm 22.7 \ddagger \\
(64.4 \pm 23.6) \dagger \\
51.7 \pm 25 \cdot 3 \ddagger \\
52 \cdot 1 \pm 22.4 \ddagger\end{array}$ & $\begin{array}{c}52.8 \pm 22.1 \ddagger \\
(52.6 \pm 27.9) \dagger \\
41.0 \pm 29.4 \ddagger \\
50.7 \pm 39.4 \dagger\end{array}$ & $\begin{array}{c}48.6 \pm 30.8 \ddagger \\
(42.5 \pm 26.5) \ddagger \\
30.6 \pm 47.3^{*} \\
65.8 \pm 25.9 \dagger\end{array}$ & $\begin{array}{c}57 \cdot 1 \pm 32 \cdot 2^{*} \\
(38.8 \pm 26 \cdot 3) \ddagger \\
58.2 \pm 31.6 \dagger\end{array}$ \\
\hline
\end{tabular}

$\ddagger \mathrm{p}<0.005$

$+\mathrm{p}<0.01$

${ }^{*} \mathrm{p}<0.02$

$\mathrm{Nm}$ was used (producing average speeds of $45 \%$ measured over the first $20 \mathrm{~ms}$, or $63 \%$ s over the first $80 \mathrm{~ms}$ ) to reduce mechanical oscillations that occur with this test. Since in one subject similar normalised results occurred with the two loads, the data from all subjects were grouped together. The data of table 1 are then the mean percentages that each component comprised of the total response. For the brachialis "resist" tests, the data in the left column were obtained with a preload due to gravity alone, and that in the right column (in parentheses) when an additional preload was used. Comparing the response distributions before and after administration of tizanidine shows that under no test condition did the drug lead to a redistribution of the responses. Such a redistribution would have occurred had the drug selectively affected any reflex component. It may be mentioned that neither were response latencies changed from their control values (M1, $23 \mathrm{~ms}$; M2, $49 \mathrm{~ms}$; M3, $76 \mathrm{~ms}$ ). Rather, as has been illustrated in figs 2 and 3 and is summarised in table 2, the amplitudes (areas under the peaks) of all responses under all test conditions were reduced. For table 2, for each subject, the size of each response component after medication was expressed as percent of the control value. The values of table 2 are the mean percentages across subjects. Thus, for example, in the brachialis "resist" tests, after medication the M1, M2 and M3 components are all reduced to about $50 \%$ of their control values. Similar results were obtained with (values in parentheses) or without an small additional preload: while the absolute size of the responses and of the level of background activity were generally larger with the small additional preload, the normalised changes were similar. For "let-go" as well as for "resist" tests, for triceps as well as for brachialis, all response components were reduced to about $50-60 \%$ of their control values. The only reduction that was not statistically significant was that of the M2 in "let-go" tests: this was probably because under these instructions the M2 was so reduced or absent (see fig 2 C) in the control runs, that further reduction was obscured.

Tizanidine also sizeably reduced the average background EMG activity: the data are presented in the first column of table 2 . For all test conditions, the average background activity with tizanidine was reduced to $50-60 \%$ of the control values, the same degree of reduction as obtained for the response components. Reduction of background activity may be seen in figs 2 and 3 by comparing the muscle activity before and after medication occurring before the onset of the torque pulse. This suggested that the decrease in the reflex responses might wholly be explained by a general depression of CNS activity, reflected in the lower background EMG rather than involving selective actions on specific reflex pathways. Such parallel variation in response sizes with background activity, for the same preload and load has been demonstrated for the monkey biceps during recovery from anaesthesia, ${ }^{26}$ and in human thumb flexor during voluntary maintenance of different levels of exertions. ${ }^{7}$ This possibility was tested for in control observations described in the next section. 
In contrast to the consistent and sizeable depressive effect of tizanidine, $400 \mathrm{mg}$ of chlormezanone (Trancopal, Winthrop Laboratories) given orally produced no consistent actions when tested at 1 and 2 hours after administration in another nine subjects (two of whom were also tested with tizanidine). Of these subjects, reflex responses and background activity (similarly at 1 and 2 hours after medication) were mainly similar or decreased from the premedication control levels in four subjects, were mainly similar or increased in another four subjects, and were mixed in the remaining subject. Averaged responses were $90 \pm 39,87 \pm 36,90 \pm 42$, and 94 \pm 46 per cent, respectively, of the control background, M1, M2 and M3 values (no additional preload, $6 \cdot 2 \mathrm{Nm}$ load, responses at 2 hours). These data, indicating ineffectiveness of chlormezanone, a mild muscle relaxant and tranquilizer, ${ }^{27} 28$ under these test conditions, serve as controls for the tizanidine data, indicating that the consistent depressive action of tizanidine was not simply due to the test situation or a placebo effect. This was further supported by observations on control subjects (reported in the next section).

Relation of reflex size to background activity. The first question to be considered was if, in the absence of drug treatment, a reduction in background EMG activity to about $50 \%$ was associated with similarly large reductions of the reflex responses. For this, the background activity and the responses of brachialis to torque perturbations, using preload torques and torque pulses similar to those used in the drug experiments, were examined in four normal subjects (three of whom had been used in the drug study). In the absence of any treatment, the level of background EMG activity occasionally varied a considerable amount for the same test conditions. (These variations were possibly due to immediate history, volition, or fatigue, although no trends toward increasing EMG activity ${ }^{21}$ or increasing mechanical displacement produced by the torque pulses, indicating fatigue, were seen during the experiments.)

In total there were nine pairs of runs where the average background activity in the "low background run" ranged from 25 to $65 \%$ of that in the paired "high background" run, differences comparable to the changes seen with tizanidine. As illustrated in fig

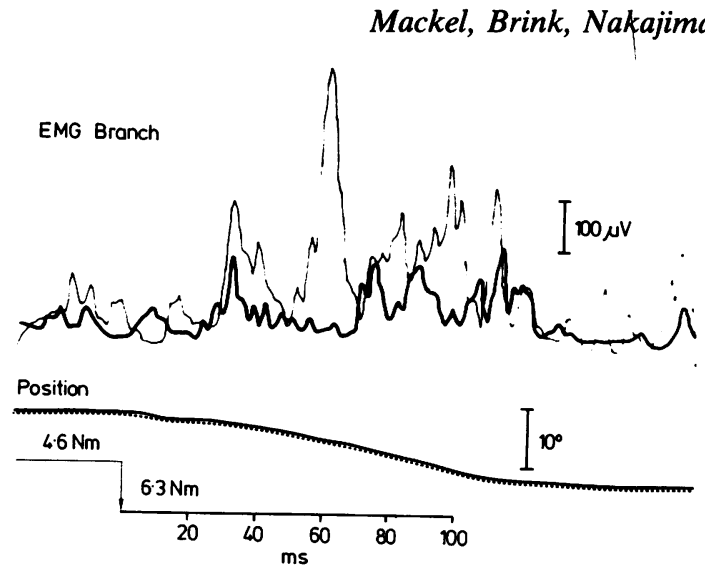

Fig 4 Relation of reflex responses to background level of EMG activity. Rectified and averaged brachialis EMG responses obtained when the background EMG activity was low (thick lines) and high (thin lines). Responses obtained under "resist" instructions, for same preload $(4 \cdot 6 \mathrm{Nm})$ and torque pulse $(6.3 \mathrm{Nm})$. There was no difference in the mechanical deviations (continuous line for high background run and broken line for low background run).

4 , and summarised in table 3 , the M1, M2 and M3 response components were decreased in parallel with decrease in background activity. Indicated in the first row of table 3 , in the nine pairs of runs, the M3 response was always smaller in the low background run (9/9), while the M1 and M2 responses were nearly always decreased. In the second row of table 3, the response amplitudes in the low background runs are expressed as percentages of the amplitudes in the paired high background runs, and the mean calculated from all trials $(n=9)$, including the responses where no change occurred. Associated with a mean reduction of background activity to $47 \%$, the reflex responses were significantly reduced to about $60-65 \%$. In addition, there were another three pairs of runs where the low background runs were associated with loss of reflex responses. These results show that large reductions in background activity are associated with equally large reductions in responses, sufficient to account for the tizanidine-induced changes.

Secondly, although in these control subjects tested over 3 hours large changes in background activity for the same stimulus conditions did some-

Table 3 Change in reflex activity associated with change in background EMG level

\begin{tabular}{|c|c|c|c|c|}
\hline & $B A$ & $M 1$ & $M 2$ & M3 \\
\hline $\begin{array}{l}\downarrow \text { with low BA } \\
\text { Mean Amplitude with low BA ( } \pm \text { SD) }\end{array}$ & $\overline{47} \pm 13$ & $\begin{array}{l}8 / 9 \\
66 \pm 27 \dagger\end{array}$ & $\begin{array}{l}7 / 9 \\
66 \pm 36^{*}\end{array}$ & $\begin{array}{l}9 / 9 \\
61 \pm 21 \ddagger\end{array}$ \\
\hline
\end{tabular}

${ }^{*} \mathrm{p}<0.05$

$\mathrm{tp}<0.01$

$\neq \mathrm{p}<0.002$

2-tailed Student's $\mathrm{t}$ test for small dependent samples 
times occur, this was much rarer than the reverse, in that the same preload led to the same background activity. Thus, for 229 pairs of trials matched for both preload and test conditions, background activity varied by less than $15 \%$ in 188 trials, or $82 \%$ of the pairs. Also, when large changes in background activity did occur there was no tendency for this to be a decrease over time: activity increased in the later trial for seven and decreased for five of the total 12 pairs of runs discussed above. These observations that background activity was, in the main, very stable over time in control subjects, add to those on the lack of consistent action of another mild agent in the same test situation, to support the conclusion that the depressed background activity and reflex responses seen on testing tizanidine were due to action of that drug.

\section{Discussion}

After im injection, tizanidine has a strong depressive, but relatively short-lasting, action on EMG background activity and on all the reflex responses to torque perturbations. Rather than being selective, the effects on the reflex responses appear to be secondary to a "general depressive" action of tizanidine as is indicated by the decrease in the background EMG activity. However, the possibility that selective actions may occur in parallel has not been ruled out: it is simply that they are not required to account for the results obtained. Although in disagreement with the conclusion of Hassan and McLellan $^{3}$ of an independent action on stretch responses, the present results are in fact in agreement with their data, where tizanidine decreased the EMG activity during both stretching and shortening phases of a sinusoidal stimulus, indicating a depression of the overall mean level of EMG activity.

In light of the present interpretation, the apparently contradictory results obtained in anaesthetised or spinalised ${ }^{1}$ or in decerebrate ${ }^{2}$ cats are understandable. In anaesthetised or spinalised cats, only weak or no reduction in monosynaptic reflexes were seen with tizanidine, and in decerebrate cats, the tonic (after $100 \mathrm{~ms}$ ) EMG activity but not the early phasic reflexes were decreased by tizanidine. In none of these experiments was the level or change in background activity monitored. However, anaesthetisation or spinalisation themselves depress spinal cord activity and consequently reflex size,$^{29}$ and this would obscure further reductions due to tizanidine. Only weak reductions may be expected in such preparations. On the other hand, decerebration leads to artificially high background activity and exaggerated stretch reflexes, ${ }^{30}$ and this could override the depressive action of tizanidine.
The decreased myotonic activity indicated decreased spinal motoneuron excitability: this could result from an action of tizanidine at the spinal cord level, and/or at a supraspinal site or sites. The sedating effects and effects on the EEG suggest supraspinal sites may be involved, although these effects could themselves be secondary to relaxed muscle tone. Neither is the mode of action of tizanidine understood: whether it interferes with excitatory transmission, or enhances inhibitory mechanisms, although the latter has been proposed. ${ }^{12}$

Spasticity is characterised by pathological overactivity in stretch reflex circuits. ${ }^{31}$ Although tizanidine does not act selectively on these circuits, through its general depressive action, it has an antispastic effect, which makes it useful for clinical application.

The torque motor was built at the Department of Electrical Engineering of the Technical University of Munich. Tizanidine was supplied by Sandoz, Ltd, Basel, Switzerland. The study was partly supported by Sonderforschungsbereich, SFB 50 .

The technical help of Mrs N Pahlke was greatly appreciated.

\section{References}

' Sayers AC, Bürki HR, Eichenberger E. The pharmacology of 5-chloro-4-(2-imidazolin-2-yl- amino)-2, 1, 3-benzothiadiazole (DS 103-282), a novel myotonolytic agent. Arzneim.-Forsch./Drug Res. 1980;30 (I): 793-803.

${ }^{2}$ Coward DA. Selective Muscle Relaxant Properties of Tizanidine and an Examination of its Mode of Action. Triangle 1981;20:151-8.

${ }^{3}$ Hassan N, McLellan DL. Double-blind comparison of single doses of DS103-282, baclofen and placebo for suppression of spasticity. $J$ Neurol Neurosurg Psychiatry 1980;43:1132-6.

${ }^{4}$ Knutsson E, Martensson A, Gransberg L. Antiparetic and antispastic effects induced by Tizanidine in patients with spastic paresis. $J$ Neurol Sci 1982;53: 187-204.

${ }^{5}$ Ringwald E, Campean JK, Gerstenbrand F, Lorincz A, Lörincz P, Ludin HP. Klinische Erfahrungen mit einem neuartigen Myotonolytikum (DS 103-282 Sandoz). Nervenarzt 1977;48:355-8.

${ }^{6}$ Hammond PH. Involuntary activity in biceps following the sudden application of velocity to the abducted forearm. J Physiol (Lond) 1955; 127:23-25 P.

${ }^{7}$ Marsden CD, Merton PA, Morton HB. Servo action in the human thumb. J Physiol (Lond) 1976;257:1-44.

${ }^{8}$ Tatton WG, Forner SD, Gerstein GL, Chambers WW, Liu CN. The effect of postcentral cortical lesions on motor responses to sudden limb displacements in monkeys. Brain Res 1975;96:108-13.

${ }^{9}$ Evarts EV. Motor cortex reflexes associated with learned movement. Science 1973;179:501-3. 
${ }^{10}$ Marsden CD, Merton PA, Morton HB. Stretch reflex and servo action in a variety of human muscles. $J$ Physiol (Lond) 1976;259:531-60.

" Ghez C, Shinoda Y. Spinal mechanisms of the functional stretch reflex. Exp Brain Res 1978;32:55-68.

12 Tracey DJ, Walmsley B, Brinkman J. 'Long-loop' reflexes can be obtained in spinal monkeys. Neurosci Lett 1980;18:59-65.

${ }^{13}$ Eklund G, Hagbarth K-E, Hägglund JV, Wallin EU. The 'late' reflex responses to muscle stretch: the 'resonance hypothesis' versus the 'long-loop hypothesis'. J Physiol (Lond) 1982;326:79-90.

${ }^{14}$ Colebatch JG, Gandevia SC, McCloskey DI, Potter EK. Subject instruction and long latency reflex responses to muscle stretch.J Physiol (Lond) 1979;292:527-34.

${ }^{15}$ Evarts EV, Granit R. Relations of reflexes and intended movements. Prog Brain Res 1976;44:1-14.

${ }^{16}$ Hammond PH. The influence of prior instructions to the subject on an apparently involuntary neuromuscular response. J Physiol (Lond) 1956;132:17-18 P.

${ }^{17}$ Chan CWY, Melvill Jones G, Kearney RE, Watt DGD. The 'late' electromyographic response to limb displacement in man. I. Evidence for supraspinal contribution. Electroencephalogr Clin Neurophysiol 1979;46:173-81.

${ }^{18}$ Marsden CD, Merton PA, Morton HB, Adam J. The effect of lesions of the sensorimotor cortex and the capsular pathways on servo responses from the human long thumb flexor. Brain 1977; 100:503-26.

${ }^{14}$ Winter DA. Biomechanics of Human Movement. New York: John Wiley and Sons, 1979.

${ }^{20}$ Crago PE, Houk JC, Hasan Z. Regulatory actions of human stretch reflex. J Neurophysiol 1976;39:92535 .
${ }^{21}$ Vredenbregt J, Rau G. Surface electromyography in relation to force, muscle length and endurance. In: Desmedt JE, ed. New Developments in Electromyography and Clinical Neurophysiology. Basel: Karger, 1973;I:607-22.

${ }^{22}$ Wilkie DR. The relation between force and velocity in human muscle. J Physiol (Lond) 1950;110:249-80.

${ }^{23}$ Gottlieb GL, Agarwal GY. Response to sudden torques about ankle in man: Myotatic reflex. J Neurophysiol 1979;42:91-106.

${ }^{24}$ Rothwell JC, Traub MM, Marsden CD. Influence of voluntary intent in the human long-latency stretch reflex. Nature 1980;286:496-8.

${ }^{25}$ Hays WL. Statistics. New York: Holt, Rinehart and Winston, 1981, 3rd ed.

${ }^{26}$ Cooke JD, Eastman MJ. Long-loop reflexes in the tranquilized monkey. Exp Brain Res 1977;27:491-500.

${ }^{27}$ Gesler RM, Coulston F. Pharmacologic and toxicologic studies of two new centrally acting skeletal muscle relaxants, chlormethazanone and dichlormethazanone. Toxicol Appl Pharmacol 1959;1:16884.

${ }^{28}$ Kearney RD. Use of Trancopal as a muscle relaxant and tranquilizer in industrial medicine: clinical experience in 220 patients. Curr Therap Res 1960;2:127-31.

${ }^{29}$ Lloyd DPC. Conduction and synaptic transmission of reflex response to stretch in spinal cats. J Neurophysiol 1943;6:317-26.

${ }^{30}$ Sherrington CS. Decerebrate rigidity and the reflex coordination of movements. J Physiol (Lond) 1898;22:319-22.

${ }^{31}$ Lance JW. Symposium synopsis in: Feldman RG, Young RR, Koella WP, eds. Spasticity: Disordered Motor Control. Chicago: Ceyrbook Medical Publishers, 1980:485. 